\section{FRESH VENOUS ALLOGRAFTS IN PERIPHERAL ARTERIAL RECONSTRUCTION IN DOGS}

\author{
Effects of \\ histocompatibility and \\ of short-term \\ immunosuppression with \\ cyclosporine $A$ and \\ mycophenolate mofetil
}

To date, no arterial substitute has been shown to be as effective as the autologous saphenous vein in peripheral revascularization procedures. In the present study, the venous allograft was evaluated as a vascular substitute in terms of patency and induction of host immune reactivity, whether used in major histocompatibility complex-incompatible, major histocompatibility complex-compatible, or immunosuppressed major histocompatibility complex-incompatible dogs. The immunosuppressive drug therapies were given for a period of 31 days, beginning 1 day before transplantation, and consisted of the use of cyclosporine A, mycophenolate mofetil, or a combination of both. All histoincompatible allografts were thrombosed at 4 or 8 weeks after transplantation with antibody development and cell-mediated cytotoxicity in the graft, whereas histocompatible allografts showed late stenosis without immunologic reactions directed toward donor cells. Given alone, neither cyclosporine A nor mycophenolate mofetil improved the overall patency of venous allografts; thrombosis occurred shortly after cessation of immunosuppression. Still, the cyclosporine A-mycophenolate mofetil combination therapy led to a $100 \%$ patency rate at 20 weeks after implantation and immune reactions were markedly reduced. This study shows that the fresh vein allograft is still an attractive and functional alternative to the autologous saphenous vein if the host immunologic reactions are controlled by cyclosporine A-mycophenolate mofetil immunosuppression. (J THORAC CARDIOVASC SURG 1995;110:1732-44)

Eric Wagner, $\mathrm{PhD},{ }^{a}$ Raynald Roy, $\mathrm{PhD},{ }^{a}$ Yves Marois, MSc, ${ }^{\mathrm{b}}$ Yvan Douville, MD, MSc, ${ }^{b, c}$ and Robert Guidoin, $\mathrm{PhD},{ }^{\mathrm{b}}$ Quebec, Quebec, Canada
$T$ he autologous saphenous vein and the internal mammary artery are the preferred blood conduits for coronary ${ }^{1,2}$ and peripheral ${ }^{3}$ arterial reconstruction. However, they can be absent or unsuitable in as many as $20 \%$ to $30 \%$ of patients. Alternative blood conduits, such as the expanded polytetrafluoroethylene prosthesis and the chemically pro-

From the Rheumatology and Immunology Research Center, Laval University Medical Center, ${ }^{a}$ the Department of Surgery, Laval University, and the Biomaterials Institute, St. François D'Assise Hospital, ${ }^{\text {b }}$ and the Department of Vascular Surgery, St. Sacrement Hospital, ${ }^{c}$ Quebec, Quebec, Canada. Supported by the Medical Research Council of Canada (grant MT-7879).

Received for publication Nov. 30, 1994.

Accepted for publication Feb. 16, 1995.

Address for reprints: Raynald Roy, $\mathrm{PhD}$, Rheumatology and Immunology Research Center, Laval University Medical Center, 2705 Laurier Blvd., Room 9800, Ste-Foy, Quebec, Canada G1V 4G2.

Copyright (C) 1995 by Mosby-Year Book, Inc.

$0022-5223 / 95 \$ 5.00+0 \quad \mathbf{1 2 / 1 / 6 4 1 6 0}$ cessed human umbilical vein graft (bioprosthesis), fail as small-caliber arterial substitutes. Indeed, they exhibit poor long-term patency rates ${ }^{4}$ because of thrombosis and susceptibility to bacterial colonization and lipid uptake. ${ }^{5}$ Only viable biologic tissue resists infection and lipid retention. ${ }^{6}$ Venous allografts were used in the past and have yielded interesting short-term results, ${ }^{7,8}$ but were later shown to be targets of immune reactions, potentially leading to allograft failure. ${ }^{9}$

Since the venous allograft tissue was shown to be antigenic, ${ }^{10}$ donor-recipient histocompatibility matching ${ }^{11-13}$ and immunosuppressive therapies ${ }^{13-16}$ have been investigated. Furthermore, cryopreservation has also been proposed as a way to reduce antigenicity and to create a bank of readily available tissues. ${ }^{17-19}$ However, conflicting results have emerged from these studies so that skepticism remains about the usefulness of venous allografts in small-diameter revascularization procedures. To determine the factors that could influence venous allograft success, the roles of histocompat- 
ibility and short-term immunosuppressive treatment were evaluated in a canine femoral artery replacement model. Cyclosporine A (CsA), a potent inhibitor of early $T$-cell activation, and mycophenolate mofetil (MMF), a new, powerful inhibitor of late T-cell and B-cell activation, were used either alone or in combination. Autografts and allografts were implanted and monitored in terms of patency, induction of thrombohematologic parameter modifications, cellular and humoral immune reactions, histologic changes, and appearance on scanning electron microscopy (SEM).

\section{Material and methods}

Dog selection and operation. Twenty-one young adult mongrel dogs (4 male and 17 female dogs) and seven Labrador retriever littermates (five male and two female dogs) approximately 1 year old and weighing 18 to $26 \mathrm{~kg}$ were selected for the present study. They were treated according to the guidelines of the Canadian Council on Animal Care. The animals were paired before vascular operation, depending on mutual major histocompatibility complex (MHC) compatibility as measured by a mixed leukocyte culture assay as previously described. ${ }^{20}$ Because allele-specific typing sera were unavailable, the mixed leukocyte culture assay is a good and recognized indicator of mononuclear cell reactivity. ${ }^{21}$ Dogs were fasted for 12 hours before the operation. They were anesthetized intravenously with $20 \mathrm{mg} / \mathrm{kg}$ sodium pentobarbital (Somnotol) and the lungs were mechanically ventilated. They received additional halothane (Fluothane) when further anesthesia was required. After groin disinfection and exploration, each dog received $10 \mathrm{~cm}$ long femoral vein segments as substitutes for both femoral arteries: an allograft was interposed in the right femoral artery, and an autograft was used as a control in the left femoral artery. To avoid prolonged ischemia, the grafting procedure was done immediately after vein excision from the donor with an end-to-end anastomotic technique. For the performance of open biopsies after operation, to thus avoid stretching of the graft, grafts were slightly looped. After operation, the dogs were returned to their cages and fed an unrestricted standard diet.

Experimental groups. The control group consisted of nine mongrel dogs and one Labrador, all paired as histoincompatible (MHC incompatible). These dogs received a fresh venous autograft and an allograft without any treatment. The second group consisted of six untreated Labrador littermates paired as histocompatible (MHC compatible). The third group consisted of four histoincompatible graft recipients that were given an olive oil solution of CsA orally at a dosage of $10 \mathrm{mg} / \mathrm{kg}$ per day for 31 days, beginning the day before transplantation. The fourth group comprised four histoincompatible dogs that received MMF in gelatin capsules orally at a dosage of 20 $\mathrm{mg} / \mathrm{kg}$ per day, also for a total of 31 days beginning 1 day before implantation. Finally, the fifth group was composed of four histoincompatible dogs that received both
CsA and MMF in the same dosages previously described and for the same period.

Thrombohematologic testing and follow-up. Changes in blood coagulation parameters were measured for each dog before transplantation, at the time of the first biopsy, and when the dogs were killed. Serum and heparinized blood samples were collected periodically after operation for donor-specific antibody screening and graft-infiltrating lymphocyte culture, respectively. Hematocrit concentration was determined by a capillary method, leukocyte and platelet counts were done by hematometry, and clotting time was done by hemochronometry. In addition, platelet aggregation was evaluated by aggregometry, and hemostasis was assessed by thromboelastography. To assess blood susceptibility to clot formation, the thrombogenic index (TI) was calculated as $\mathrm{TI}=\mathrm{Emx} / \mathrm{k}$, where Emx is the clot elasticity factor as obtained by the conversion of Am (clot stiffness, millimeters) according to a thromboelastograph conversion table provided by the company (Hellige, Freiburg, Germany) and $\mathrm{k}$ is the start of clot formation (minutes).

Graft patency was determined at periodic intervals by Doppler ultrasonographic evaluation. The dogs were killed 5 months after transplantation or when an allograft showed no indication of blood flow.

Vascular endothelial cell culture. To measure host immune reactions directed toward the allograft, a segment of jugular vein was excised from each dog the same day the transplantation procedure took place, and vascular endothelial cells (ECs) were isolated according to the method of Jaffe and associates. ${ }^{22}$ They were cultured in medium 199 supplemented with heat-inactivated fetal bovine serum, EC growth supplement, heparin, fresh glutamine, and antibiotics, as previously described. ${ }^{18} \mathrm{Cul}-$ tures had to reach the third passage before the cells could be used.

Donor-specific antibody screening and cytotoxicity testing. The development of posttransplant antibodies was measured by indirect immunofluorescence with use of a flow-cytometric assay as previously described. ${ }^{20}$ Vascular graft recipients were screened for antibody formation with serum samples collected at $0,2,4$ or $5,8,12,16$, and 20 weeks after operation. Sera were tested against donor, recipient, and third-party ECs and splenocytes (obtained at the animal's death). A reaction was considered positive when a serum exhibited a shift of at least 10 mean fluorescence channels compared with findings in the control serum (pooled normal dog serum).

The cytotoxic activity of flow-cytometric reactive sera was assessed by a cytotoxic flow-cytometric assay. In brief, ECs were incubated with the corresponding serum and washed thoroughly. They were then incubated with rabbit complement to which propidium iodide was added, washed thoroughly, and fixed in paraformaldehyde before being analyzed on a flow cytometer (FACSort, Becton Dickinson, San Diego, Calif.). A positive cytotoxic reaction was observed when a shift of at least 10 mean red fluorescence channels was measured for a given serum, compared with findings in the control serum.

Cellular immune reactivity. Graft-infiltrating alloreactive lymphocytes were cultured from samples obtained by open autograft and allograft biopsies done at 2 and 4 
Table I. Graft patency in littermates, unrelated dogs, and immunosuppressed dogs

\begin{tabular}{|c|c|c|c|c|c|c|c|c|}
\hline \multirow[b]{2}{*}{ Experimental group ${ }^{*}$} & \multicolumn{8}{|c|}{ Patency rate (No. of patent grafts) by time (wk) } \\
\hline & 0 & 2 & $4 \dagger$ & $5+$ & 8 & 12 & 16 & 20 \\
\hline \multicolumn{9}{|l|}{ Histocompatible } \\
\hline \multicolumn{9}{|l|}{ Littermates } \\
\hline Autografts & $6 / 6$ & $6 / 6$ & $6 / 6$ & & $6 / 6$ & $6 / 6$ & $5 / 6$ & $4 / 6$ \\
\hline Allografts & $6 / 6$ & $4 / 6$ & $4 / 6$ & & $4 / 6$ & $4 / 6$ & $2 / 6$ & $1 / 6$ \\
\hline \multicolumn{9}{|l|}{ Histoincompatible } \\
\hline \multicolumn{9}{|l|}{ Untreated } \\
\hline Autografts & $10 / 10$ & $10 / 10$ & $9 / 10$ & & $9 / 10$ & $9 / 10$ & $9 / 10$ & $9 / 10$ \\
\hline Allografts & $10 / 10$ & $7 / 10$ & $3 / 10$ & & $1 / 10$ & $0 / 10$ & & \\
\hline \multicolumn{9}{|l|}{ CsA } \\
\hline Autografts & $4 / 4$ & $4 / 4$ & & $2 / 4$ & $2 / 4$ & $2 / 4$ & & \\
\hline Allografts & $4 / 4$ & $4 / 4$ & & $2 / 4$ & $1 / 4$ & $0 / 4$ & & \\
\hline \multicolumn{9}{|l|}{ MMF } \\
\hline Autografts $\ddagger$ & $4 / 4$ & $4 / 4$ & & $2 / 3$ & $2 / 3$ & & & \\
\hline Allografts & $4 / 4$ & $4 / 4$ & & $1 / 4$ & $0 / 4$ & & & \\
\hline \multicolumn{9}{|l|}{$\mathrm{CsA}+\mathrm{MMF}$} \\
\hline Autografts & $4 / 4$ & $4 / 4$ & & $3 / 4$ & $3 / 4$ & $3 / 4$ & $3 / 4$ & $3 / 4$ \\
\hline Allografts & $4 / 4$ & $4 / 4$ & & $4 / 4$ & $4 / 4$ & $4 / 4$ & $4 / 4$ & $4 / 4$ \\
\hline
\end{tabular}

${ }^{*}$ Experimental groups were as follows: Littermates, untreated histocompatible littermates; Untreated, untreated histoincompatible dogs; CSA, CsA-treated histoincompatible dogs; $M M F$, MMF-treated histoincompatible $\operatorname{dogs} ; \operatorname{Cs} A+M M F$, histoincompatible dogs treated with CsA and MMF.

fGraft patency was assessed at 4 weeks in untreated dogs and at 5 weeks in immunosuppressed dogs at performance of the first biopsy.

\$Only three of the four autografts could be evaluated for graft patency because of severe infection and necrosis in one dog's leg observed at 5 weeks.

weeks for dogs without immunosuppressive therapy and at 5 weeks for those receiving drug therapies. This procedure was also done when the dogs were killed. The biopsy technique was as follows. After graft exploration, a $1 \mathrm{~cm}$ medial vein graft segment was excised and the graft was reclosed by end-to-end anastomoses. Lymphocytes were cultured according to the method of Dal Col and associates. ${ }^{23}$ In brief, biopsy sample fragments were divided into 10 to 15 pieces and cultured in a 96-well, round-bottomed microtiter plate in RPMI 1640 medium supplemented with $10 \%$ heat-inactivated pooled dog serum, fresh glutamine, antibiotics, $50 \mathrm{U} / \mathrm{ml}$ interleukin-2, and $10^{5}$ irradiated ( 3000 rads) autologous feeder mononuclear cells. The medium was changed periodically, with the addition of feeder cells once a week until sufficient growth was noted (usually 4 weeks). Cultured lymphocytes were then tested for cytotoxic activity against donor, recipient, and thirdparty ECs in a 4-hour ${ }^{51} \mathrm{Cr}$ release assay. Target cells $\left(10^{6}\right)$ were labeled with $100 \mu \mathrm{Ci}$ of $\mathrm{Na}_{2}{ }^{51} \mathrm{CrO}_{4}$ for 90 minutes at $37^{\circ} \mathrm{C}$. Then they were incubated with cultured graft-infiltrating lymphocytes at effector/target ratios of $10: 1$ and $40: 1$ in a total of $200 \mu 1$ of culture medium devoid of interleukin-2 in a 96-well, roundbottomed plate. After a 4-hour incubation, $100 \mu \mathrm{l}$ of supernatant was removed and counted on a gamma counter. Spontaneous ${ }^{51} \mathrm{Cr}$ release was determined by incubating target cells alone, whereas maximal release was determined by treating the labeled target cells with $10 \%$ Triton X-100 polyoxyethylene (Union Carbide Corp., Danbury, Conn.). The percentage of specific EC lysis was calculated as follows:
Specific ${ }^{51} \mathrm{Cr}$ release $=$

$\begin{gathered}\begin{array}{c}\text { Experimental release } \\ (\mathrm{cpm})\end{array}-\begin{array}{c}\text { Spontaneous release } \\ (\mathrm{cpm})\end{array} \\ \frac{\begin{array}{c}\text { Maximal release } \\ (\mathrm{cpm})\end{array}}{\text { Spontaneous release }}(\mathrm{cpm})\end{gathered} \times 100$

Graft processing and analysis. A fragment of a biopsy specimen and representative anastomotic and midportions of explanted grafts (obtained at death) were fixed in 10\% formalin and later processed for light microscopy and SEM. Paraffin sections $5 \mu \mathrm{m}$ thick were stained with Weigert's stain to reveal elastic fibers and Masson's trichrome stain to differentiate fibrin from collagen. Specimens for SEM evaluation were postfixed in carboxyhydrazide and osmium tetroxide. Dehydration was obtained by immersion of the specimens in a series of ethanol solutions, culminating in pure ethanol, followed by critical-point drying with liquid $\mathrm{CO}_{2}$ used as the transfer medium. They were then coated with a gold-plated alloy before observation under a Jeol JSM35 SEM (Soquelec, Montreal, Quebec, Canada) at a 15 $\mathrm{kV}$ accelerating voltage.

\section{Results}

Graft patency. Dogs in each experimental group were evaluated periodically by Doppler ultrasonography for graft patency. The results are shown in Table I. Surprisingly, the autografts in each group exhibited different patency rates. In the group of untreated histoincompatible dogs, only one autograft thrombosed, which was attributed to a tech- 
nical failure. Two of six autografts were stenosed at the end of the protocol (20 weeks) in the group of histocompatible littermates. Two autografts occluded early after implantation among the four dogs treated with CsA, one of three failed in dogs treated with MMF, and three of four remained patent at 20 weeks in dogs receiving a combined immunosuppressive therapy (CsA and MMF).

In the untreated histoincompatible group of dogs, four allografts underwent thrombosis at 4 weeks and two thrombosed at 8 weeks. Three dogs had a thrombosed allograft at 2 weeks and one had a stenosed allograft at 12 weeks. Two early thromboses at 2 weeks and three stenoses (two at 16 weeks and one at 20 weeks) occurred in the group with histocompatible allografts (littermates). Only one allograft remained patent for the 20-week implantation schedule. Allografts implanted in CsAtreated dogs thrombosed at 5 (in two dogs), 7, and 11 weeks, respectively. Treatment with MMF was also unsuccessful, with three thrombosed allografts at 5 weeks and one at 8 weeks. However, in the group of dogs treated with the combined immunosuppressive treatment composed of both CsA and MMF, all four allografts were patent at 20 weeks after implantation. Three of the explanted grafts exhibited a nonocclusive thin mural thrombus in the midportion, whereas the remaining allograft showed a thrombus-free luminal surface.

Thrombohematologic parameters. The three untreated histoincompatible dogs, which underwent allograft thrombosis at 2 weeks after transplantation, showed high TI values at operation (data not shown). However, the TI was found to be homogeneous among all other dogs before implantation and was shown to increase when thrombosis occurred. All other hematologic parameters did not differ from one blood collection to another. In the group of untreated histocompatible littermates, the hematologic parameters were not altered by the grafting procedure. One of the MHC compatible dogs had a high TI at operation and underwent allograft thrombosis at 2 weeks. Finally, within the immunosuppressed dog groups, no differences in hematologic parameters were noted except a reduction of about $50 \%$ of the circulating white blood cell counts in two dogs treated with cyclosporine at 5 weeks after operation (data not shown).

Antidonor antibody development. Recipient dogs were investigated for antidonor antibody formation with the use of donor, recipient, and third-party cultured vascular ECs and splenocytes (obtained
Table II. Posttransplant donor-specific antibodies

\begin{tabular}{|c|c|c|c|}
\hline \multirow[b]{2}{*}{ Experimental group ${ }^{*}$} & \multicolumn{2}{|c|}{$\begin{array}{l}\text { Posttransplant } \\
\text { antibody } \\
\text { developmentt }\end{array}$} & \multirow{2}{*}{$\begin{array}{c}\text { Cytotoxicity } \\
\text { on } E C s t\end{array}$} \\
\hline & Spleen cells & $E C s$ & \\
\hline \multicolumn{4}{|l|}{ Histocompatible } \\
\hline Littermates $(n=6)$ & $0 / 6$ & $0 / 6$ & NA \\
\hline \multicolumn{4}{|l|}{ Histocompatible } \\
\hline Untreated $(n=8)$ & $8 / 8$ & $8 / 8$ & $8 / 8$ \\
\hline $\operatorname{CsA}(n=4)$ & $1 / 4$ & $3 / 4$ & $2 / 3$ \\
\hline $\mathrm{MMF}(n=4)$ & $3 / 4$ & $1 / 1 \S$ & $0 / 1 \S$ \\
\hline $\mathrm{CsA}+\operatorname{MMF}(n=4)$ & $1 / 4$ & $1 / 2 \S$ & $0 / 1 \S$ \\
\hline
\end{tabular}

$N A$, Not applicable.

${ }^{*}$ Experimental groups were as follows: Littermates, untreated histocompatible littermates; Untreated, untreated histoincompatible $\operatorname{dogs;} C s A, \operatorname{CsA}$ treated dogs; $M M F$, MMF-treated dogs; $C s A+M M F$, dogs treated with CsA and MMF.

†Posttransplant antibody development was measured with the use of donor splenocytes and cultured vascular ECs in a flow-cytometric assay.

$\ddagger$ The cytotoxic activity of postransplant antibodies was evaluated by a fluorescent cytotoxicity assay with donor cultured vascular ECs.

$\S$ Vascular ECs could not be cultured in three dogs treated with MMF and in two dogs treated with CSA and MMF at the time of implantation or at the dog's death.

when the dogs were killed). Cytotoxic activity of developed antibodies was also measured against donor ECs. As shown in Table II, posttransplant antibodies developed in all untreated histoincompatible dogs that reacted specifically against both donor splenocytes and ECs but not against autologous or third-party cells. These antibodies appeared at 4 weeks after implantation in seven dogs and at 2 weeks in one, and remained in the recipient serum until graft occlusion occurred. Two other dogs with early allograft thrombosis ( 2 weeks) did not show the development of antibodies. Furthermore, all dogs had posttransplant antibodies of the immunoglobulin $G$ isotype (data not shown) that were cytotoxic to donor ECs (Table II). In contrast, no untreated MHC-compatible littermates had posttransplant antibodies despite the low patency rates. Antibodies against donor ECs developed in three out of four CsA-treated dogs, only one of which had a cross reactivity with donor splenocytes, suggesting that in two of three cases antibodies were directed against EC-specific antigens. Moreover, two of the three dogs in which antibodies developed exhibited cytotoxic activity against donor ECs. Unfortunately, we could obtain ECs from only one dog in the group of recipients treated with MMF. Antibody-mediated reactions were noted in this case, but there was no cytotoxic activity. Still, three out of four dogs in this group formed antibodies against donor spleen cells. In addition, only one dog that was immunosup- 
Table III. Graft-infiltrating alloreactive lymphocytes

\begin{tabular}{|c|c|c|c|c|c|c|}
\hline \multirow[b]{3}{*}{ Explanted grafts } & \multicolumn{6}{|c|}{ Biopsy growth (No. of cultures) } \\
\hline & \multicolumn{2}{|c|}{$\begin{array}{c}\text { First } \\
\text { biopsy* }\end{array}$} & \multicolumn{2}{|c|}{$\begin{array}{l}\text { Second } \\
\text { biopsy* }\end{array}$} & \multicolumn{2}{|c|}{ Death* } \\
\hline & Pos. & Neg. & Pos. & Neg. & Pos. & $\mathrm{Neg}$ \\
\hline $\begin{array}{l}\text { Autografts }(n=28) \dagger \\
\text { Allografts }\end{array}$ & 3 & 18 & 0 & 8 & 2 & 26 \\
\hline \multicolumn{7}{|l|}{ Histocompatible } \\
\hline $\begin{array}{l}\text { Littermates } \\
\quad(n=6)\end{array}$ & 0 & 4 & 0 & 4 & 0 & 6 \\
\hline \multicolumn{7}{|l|}{ Histoincompatible } \\
\hline $\begin{array}{l}\text { Untreated } \\
\qquad(n=10)\end{array}$ & 6 & 0 & 1 & 1 & 9 & 1 \\
\hline $\operatorname{CsA}(n=4)$ & 0 & 2 & & & 0 & 4 \\
\hline $\operatorname{MMF}(n=4)$ & 0 & 0 & & & 0 & 3 \\
\hline $\begin{array}{c}\mathrm{CsA}+\mathrm{MMF} \\
(n=4)\end{array}$ & 0 & 4 & & & 0 & 4 \\
\hline
\end{tabular}

Pos., Positive; Neg., negative.

${ }^{*}$ Open biopsies were done at 2 (first biopsy) and 4 (second biopsy) weeks after operation. The culture procedure also took place when the dogs were killed using a representative midportion specimen of the entire explanted graft. In the immunosuppressive drug-treated groups, the first and only biopsy was done at 5 weeks after implantation. The results represent the number of specimens in each group in which negative or positive $(>10 \times$ $10^{6}$ cells) lymphocyte growth was observed.

$\dagger$ Autografts implanted in each experimental group were considered all together in this table.

pressed with both CsA and MMF showed the development of antibodies against donor ECs and splenocytes, but without cytotoxic activity. Again, we could not culture ECs from two dogs in the latter group, probably because of an effect of MMF on ECs.

Graft-infiltrating alloreactive lymphocytes. To assess the role of cell-mediated immune reactions in the outcome of venous allografts, graft-infiltrating alloreactive lymphocytes were cultured from biopsy specimens taken after operation and at the dog's death. Results relative to positive culture growth from each biopsy specimen and explant obtained at the recipient's death are shown in Table III. Growth was observed mostly with biopsy specimens taken from untreated histoincompatible dog allografts. Indeed, 9 of 10 dogs had specimens at death that showed positive lymphocyte growth within 1 month of culture. Moreover, all six first biopsy specimens and one of two second biopsy specimens showed growth of alloreactive lymphocytes, whereas two were contaminated (not shown). Cells obtained from these cultures demonstrated cytolytic activity against donor ECs (Table IV). In some cases, a certain level of cytotoxic activity was measured against third-party ECs, which suggested that the reactivity was directed against a common antigenic determinant. Among 21 first biopsy specimens, graft-infiltrating lymphocyte growth was seen in three autografts, whereas it appeared in 2 of 28 autograft specimens obtained at death. One of the autografts with cell growth thrombosed at 4 weeks, but cytotoxic reactivity was observed against the ECs of the allograft donor. In the immunosuppressed dog groups, no growth was observed. Three first biopsy cultures and one culture obtained at death could not yield lymphocyte growth because of contamination in the group of dogs treated with MMF (data not shown). Thus the cytotoxic activity of cells infiltrating these allografts could not be evaluated.

Histologic findings. Autografts in all groups generally showed similar histologic features regardless of the group. Indeed, except for those with early failures ( 7 of 28), autografts showed no important morphologic changes. They exhibited smooth luminal surfaces devoid of thrombus, limited intimal hyperplasia, and a low-grade inflammatory reaction, regardless of the time of sampling (Fig. 1, $A$ ). Because no important histologic change was observed in the majority of autografts, we can suppose that the biopsy procedure did not induce events such as thrombosis or intimal hyperplasia by itself. Still, allografts demonstrated a different pattern of morphologic changes. As soon as 2 weeks after operation, untreated histoincompatible allografts showed intimal destruction with deposition of fibrin on the luminal surface. Lymphocytic infiltration was frequently noted within the intima and the adventitia of the graft (Fig. 1, B). At 4 or 8 weeks, or both times, thrombus deposition onto the luminal surface was observed with decreased lymphocytic infiltration, located mainly in the adventitia (Fig. 1, C). Intimal thickening was absent in most cases but limited in a small proportion of allografts biopsied or explanted at the time the dogs were killed.

Allografts in the group of untreated histocompatible littermates either thrombosed soon after operation or had stenosed by the time the dogs were killed (5 months), except in one case in which patency was seen. In the latter case, histologic findings were comparable to those of autografts (Fig. 2, A). However, in the two stenosed allografts, no particular histologic change was noted at 2 weeks after transplantation, but important intimal hyperplasia was observed at the time of retrieval (Fig. 2, $B)$. Furthermore, the elastic network and vein structure were disorganized in these grafts. In the groups of dogs treated either with CsA or MMF, histologic findings were comparable. Indeed, at 5 weeks after implantation, thrombus deposition was observed on 
Table IV. Cytotoxic activity of graft-infiltrating lymphocytes in untreated histoincompatible dogs

\begin{tabular}{|c|c|c|c|c|c|c|}
\hline \multirow[b]{3}{*}{ Graft recipients* } & \multicolumn{6}{|c|}{ Percentage of specific EC lysist } \\
\hline & \multicolumn{3}{|c|}{ Donor } & \multicolumn{3}{|c|}{ Third party } \\
\hline & $\begin{array}{c}\text { First } \\
\text { biopsy }\end{array}$ & $\begin{array}{c}\text { Second } \\
\text { biopsy }\end{array}$ & Explant & $\begin{array}{c}\text { First } \\
\text { biopsy }\end{array}$ & $\begin{array}{l}\text { Second } \\
\text { biopsy }\end{array}$ & Explant \\
\hline \multicolumn{7}{|l|}{ Autografts $(n=2 / 3)$} \\
\hline 283 & 24.3 & & 5.1 & 0 & & 0 \\
\hline 50 & 20.1 & & 0 & 0 & & 0 \\
\hline \multicolumn{7}{|l|}{ Allografts $(n=6 / 9)$} \\
\hline 283 & 52.3 & & 71.3 & 13.5 & & 0 \\
\hline 284 & 16 & & 71.7 & 0 & & 12.5 \\
\hline 40 & 9.5 & 3.9 & 31.8 & 0 & 0 & 15.9 \\
\hline 49 & ND & & 18.1 & ND & & 0 \\
\hline 50 & 12.5 & & 0 & 0 & & 4.6 \\
\hline 285 & 25.9 & & 20.3 & 16.8 & & 12.6 \\
\hline
\end{tabular}

$N D$, Not done because of culture contamination.

${ }^{*}$ Displayed are the graft recipients for which a positive lymphocyte-infiltrating growth was observed with either biopsy or explant (obtained at death) specimens or both. Only data from dogs with positive cellular cytotoxicity are presented. The number identifying each dog is given at the left of the table. †Cytotoxicity of graft-infiltrating cultured lymphocytes was evaluated against donor and third-party ECs and was expressed as the percentage of specific ${ }^{51} \mathrm{Cr}$ release as detailed in the Materials and methods section. Displayed results correspond to an effector/target ratio of 40:1.

the luminal surface of most of the allografts, with destruction of the intima in all cases. In addition, mild to moderate mononuclear cell infiltration was observed in all layers of the vein wall, whereas subintimal fibrosis was either absent or limited (Fig. $2, C)$.

At 5 weeks, allografts from dogs treated with CsA and MMF showed a moderate inflammatory reaction within the media (Fig. 3, $A$ ) and dispersed areas of thin fibrin deposition onto the luminal surface in some cases. When the dogs were killed ( 20 weeks), these allografts showed a well-preserved vein structure. No mononuclear cell infiltration was observed, and a thin layer of fibrin or reorganizing thrombus (Masson's trichrome-positive stain, not shown) was observed on the luminal surface in the midportion (Fig. 3, B) but was absent from the anastomotic regions (Fig. 3, $C$ ). In addition, intimal hyperplasia was seen only in the midportions of these allografts (Fig. 3, B), and it did not appear to be concentric.

SEM evaluation. Autografts usually showed smooth luminal surfaces covered by endotheliumlike cells (Fig. 4, $A$ ). Nevertheless, some denuded areas were exposed to the blood flow, but without deposition of any thrombotic material. Untreated MHC-incompatible allografts, however, showed only limited coverage by endothelium-like cells at the anastomotic regions (Fig. $4, B$ ), whereas the midportions demonstrated complete loss of ECs with heavy deposition of thrombotic material (Fig. $4, C)$. This pattern of luminal covering by endothelial-like cells was also similar to that in all throm- bosed allografts and autografts in both CsA-treated dogs and MMF-treated dogs. In contrast, allografts in dogs treated with a combination of CsA and MMF showed smooth luminal surfaces after 20 weeks of implantation. Anastomotic regions were partially covered with endothelial-like cells (Fig. 5, $A$ ), usually without any thrombotic material deposition. Interestingly, endothelial-like cells were also observed in the midportions of these allografts with thin thrombotic material present on subendothelial areas (Fig. 5, B).

\section{Discussion}

The venous allograft represents an interesting alternative to the use of the autologous saphenous vein or the internal mammary artery in small-caliber arterial reconstruction because, in contrast to synthetic prostheses and bioprostheses, it is resistant to lipid uptake and bacterial colonization. ${ }^{5}$ However, its antigenicity causes host immunologic reactions that can lead to graft failure. ${ }^{24}$ Donor-recipient $\mathrm{ABO}$ compatibility was proposed in the past for improving the patency of venous allografts, ${ }^{25}$ but was finally found to have no effect on graft occlusion. ${ }^{26}$. With the objective of improving the patency rate of venous allografts and to determine the factors involved in graft occlusion, we used a canine model for femoral artery replacement. The effect of MHC compatibility was evaluated, as well as a short-term immunosuppressive treatment with CsA alone, MMF alone, or these two drugs in combination. 

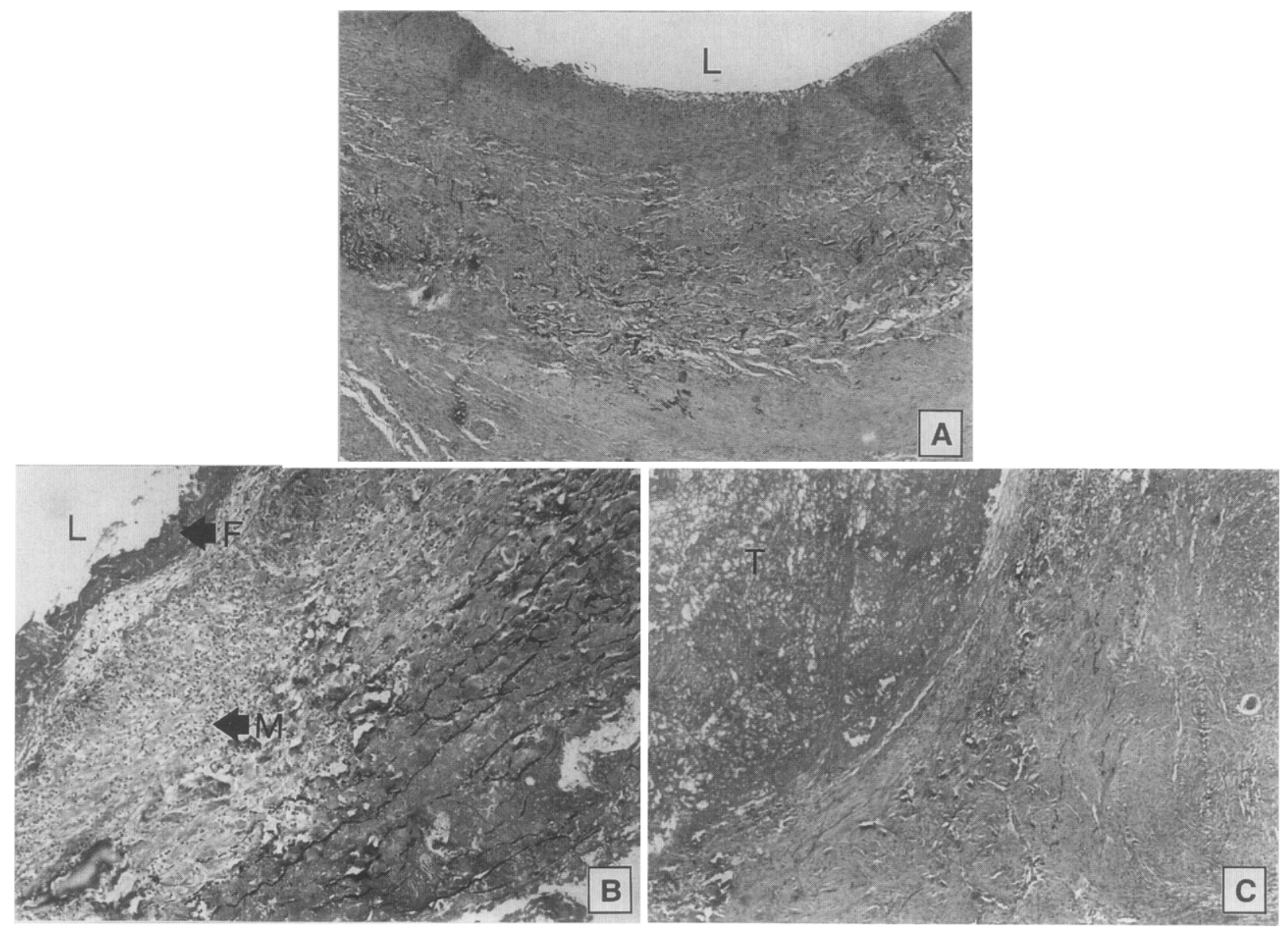

Fig. 1. A, Representative section of autograft explanted at 8 weeks showing normal vein wall structure (Weigert's stain, original magnification $\times 12.5$ ). B, Untreated histoincompatible allograft biopsied at 2 weeks after transplant showing heavy mononuclear cell infiltration $(M)$ within intima and media, with fibrin $(F)$ deposition onto the luminal surface (original magnification $\times 25$ ). $\mathbf{C}$, Untreated histoincompatible allograft explanted at 4 weeks with heavy thrombus $(T)$ occluding the luminal surface and markedly reduced cellular infiltration but destruction of intima and disorganization of wall structure (original magnification $\times 12.5$ ). L, Luminal surface.

As expected from previous reports, ${ }^{27}$ all the allografts in the group of untreated histoincompatible dogs underwent early thrombosis, usually 4 or 8 weeks after operation. Three of these allografts thrombosed at 2 weeks but were originally implanted in dogs with a high TI value at implantation. Thus the TI could explain why graft occlusion occurred so early without signs of immune reactions in two of these three dogs. Donor-specific posttransplant antibodies developed in all histoincompatible recipients of vein allografts in the untreated group except in two with a thrombosed allograft at 2 weeks. Those antibodies appeared at 2 weeks in one case or 4 weeks in all other cases, remained present in the recipient's serum until graft occlusion was observed, and had a cytotoxic activity on donor cultured vascular ECs (Table II). Characterization of posttransplant antibodies revealed that they were of immunoglobulin G isotype and that their cytotoxic activity was directed against antigens present on both donor splenocytes and ECs, presumably MHC antigens. ${ }^{20}$ Lymphocytotoxic antibodies were also found in venous allografts implanted in the $\operatorname{dog}^{28}$ and miniature swine ${ }^{13}$ and correlated with allograft failure. In addition, culture of graft-infiltrating lymphocytes allowed us to uncover the involvement of cytotoxic $T$ cells in the vein allograft rejection process. Indeed, a high proportion of biopsy and explant allograft specimens in histoincompatible untreated dogs showed positive cell 

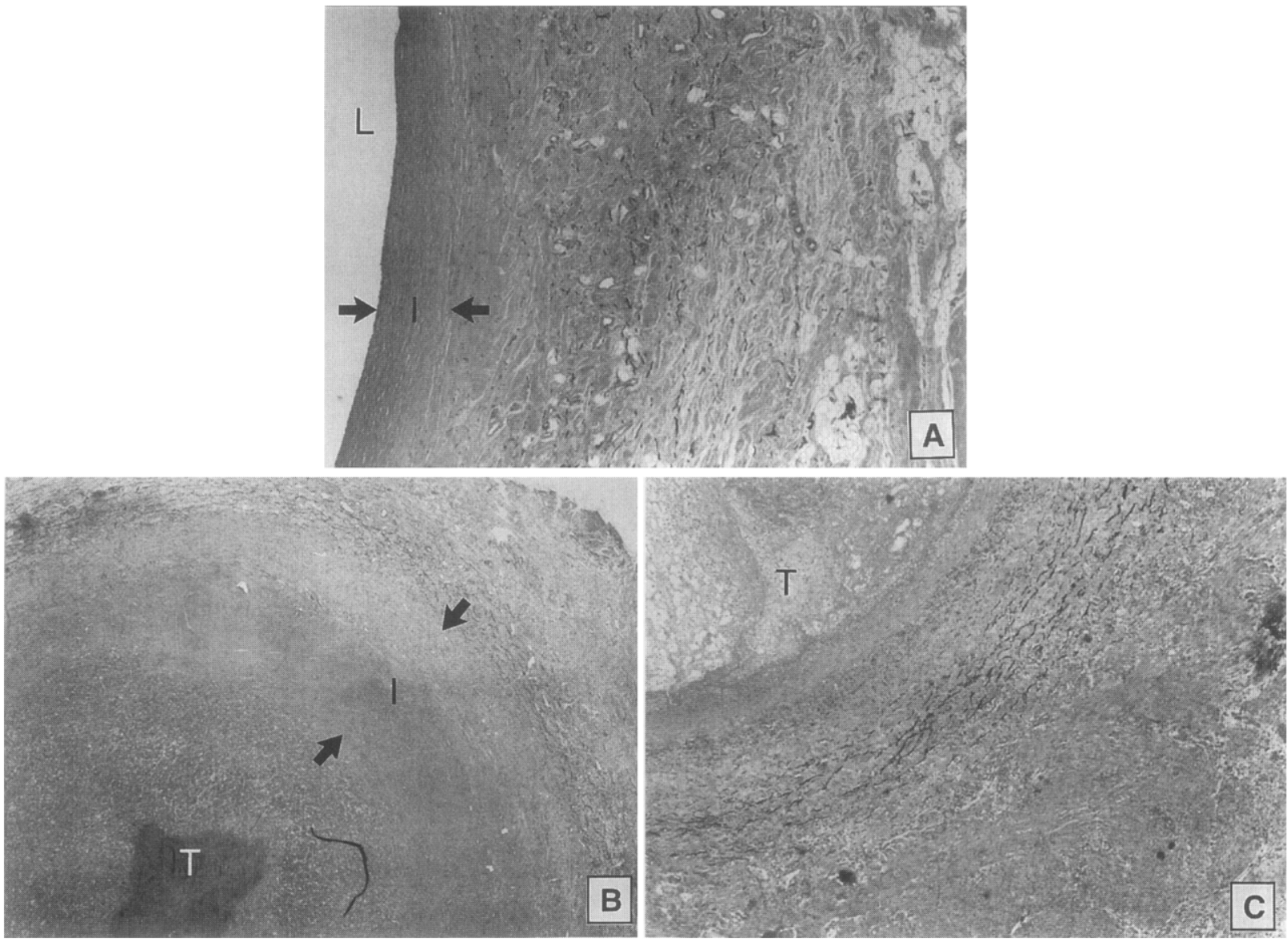

Fig. 2. A, Histologic staining of the only histocompatible allograft that was patent at 20 weeks. Endothelium is well preserved, and moderate intimal thickening $(I)$ is present (original magnification $\times$ 12.5). B, MHC-compatible allograft explanted at 16 weeks because of stenosis. Thrombus $(T)$ is present on the luminal surface and important intimal thickening $(I)$ is observed (original magnification $\times 12.5$ ). $\mathrm{C}$, Allograft from a dog treated with CsA explanted at 5 weeks showing moderate cellular infiltration within intima and media at 5 weeks and unorganized obstructive thrombus $(T)$ lying on the luminal surface (original magnification $\times 25$ ). $L$, Luminal surface.

growth (Table III) and cytolytic activity toward donor ECs (Table IV). We suspect that cells grown from allograft specimens were cytotoxic $\mathrm{T}$ cells because, in some cases tested, no cell-mediated cytotoxicity was measured against the K562 cell line (sensitive to natural killer cell-mediated lysis), P815 cell line (resistant to natural killer cell-mediated lysis), and HL60 cell line (sensitive to lysis mediated by lymphokine-activated killer cells) (data not shown). Cell growth was observed in some autograft specimens, but cytolytic activity was directed only against ECs from the allograft donor. These results support the hypothesis according to which cellular infiltration is directly involved in the occlusion of venous allografts. ${ }^{29}$ In kidney ${ }^{30}$ and cardiac ${ }^{31}$ trans- plantation, graft-infiltrating cytotoxic $\mathrm{T}$ lymphocytes are recognized as good indicators of acute rejection phenomena and show donor-specific lytic reactivity. Our results thus correlate with those obtained in other transplantation systems.

Histocompatible allografts from canine littermates exhibited a poor patency rate at 20 weeks after transplantation ( 1 in 6 ). In general, MHC compatibility only prolonged the patency of venous allografts but did not prevent late failure. This finding correlates with results reported by Stevens and colleagues, ${ }^{13}$ who used the miniature swine model, and Calhoun and colleagues, ${ }^{32}$ who used canine littermates. In both studies, MHC-compatible venous allografts thrombosed later than MHC- 

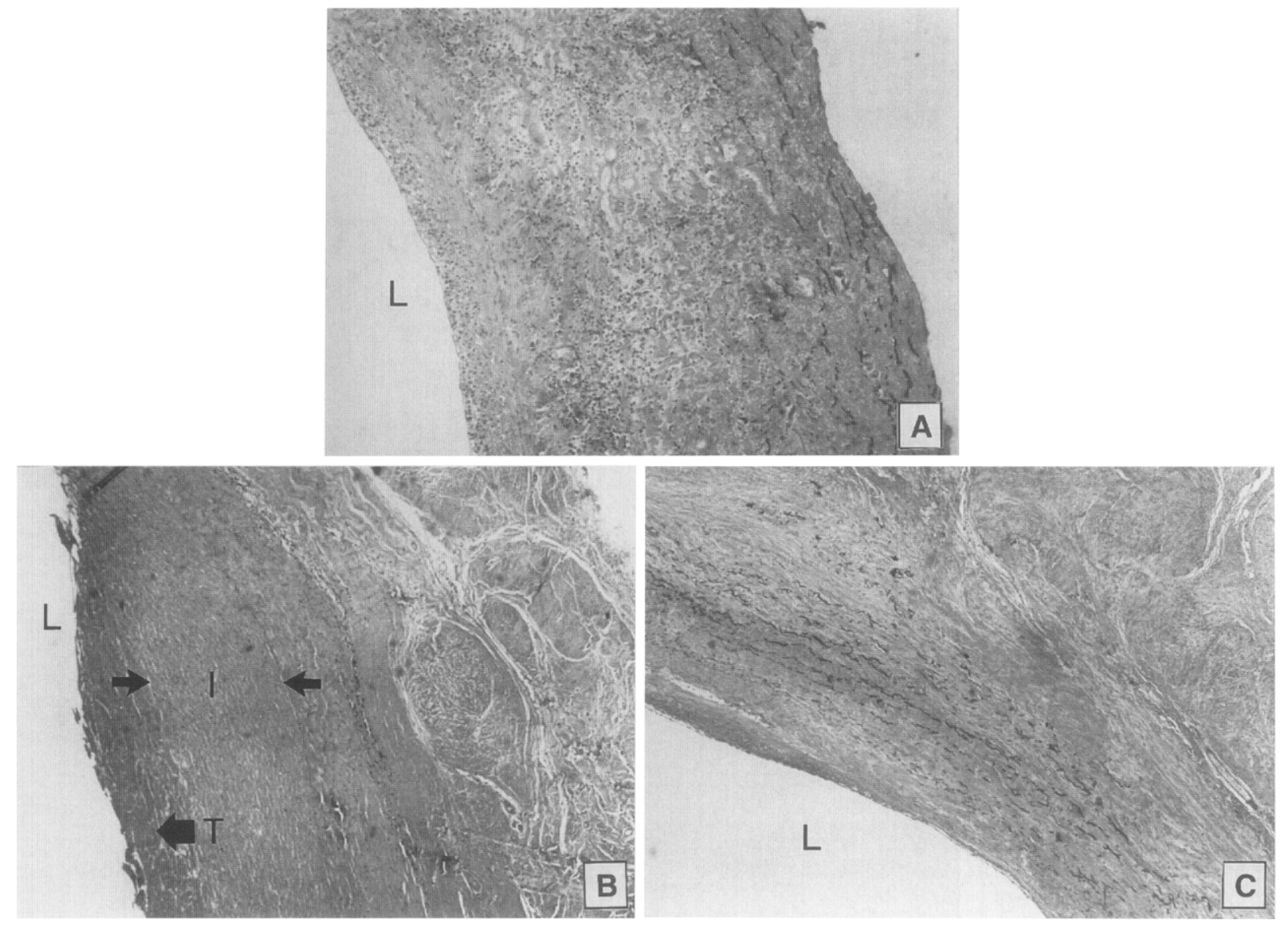

Fig. 3. Histologic stainings of allografts from dogs treated with CsA and MMF that remained patent for 20 weeks after operation. A, Five-week biopsy specimen of an allograft showing normal wall organization and moderate cellular infiltration (original magnification $\times 25$ ). B, Allograft explanted at 20 weeks showing organized thrombus $(T)$ over a nonconcentric area of intimal thickening $(I)$ in midportion (original magnification $\times 12.5$ ). C, Almost unmodified wall structure observed at anastomotic sites of an allograft explanted at 20 weeks after operation (distal portion of graft, original magnification $\times 12.5$ ). $L$, Luminal surface.

incompatible grafts. However, long-term patency was not observed, as in our experiments. In our study, factors other than immunologic reactions are probably at the origin of graft failure, inasmuch as neither antibody development nor graft-infiltrating alloreactive lymphocytes could be found in the littermates. Another process could also be responsible for the uncontrolled intimal thickening that led to graft stenosis. However, one allograft remained patent at 20 weeks without major morphologic changes within the wall structure (Fig. 2, A). Thus, in certain cases, MHC compatibility could lead to results similar to those seen with the use of autologous tissues as was proposed in previous studies. ${ }^{12}$

To achieve better patency rates, we used immu- nosuppressive therapies: CsA, MMF, and a combination of these two were assayed in a 1-month protocol, beginning the day before operation, thus avoiding the long-term side effects seen in prolonged systemic immunosuppression. CsA is a reference immunosuppressive agent that is therapeutically used to prevent solid organ transplant rejection. ${ }^{33}$ It specifically acts on the helper $\mathrm{T}$ cell by inhibiting early activation and $\mathrm{T}$ cell-mediated functions. ${ }^{34} \mathrm{MMF}$ is a semisynthetic derivative of mycophenolic acid, which is a noncompetitive, reversible inhibitor of the de novo purine biosynthesis on which $T$ and $B$ lymphocytes strictly depend for deoxyribonucleic acid replication and thus acts on the late stage of activation. ${ }^{35}$ Because MHC-incom- 

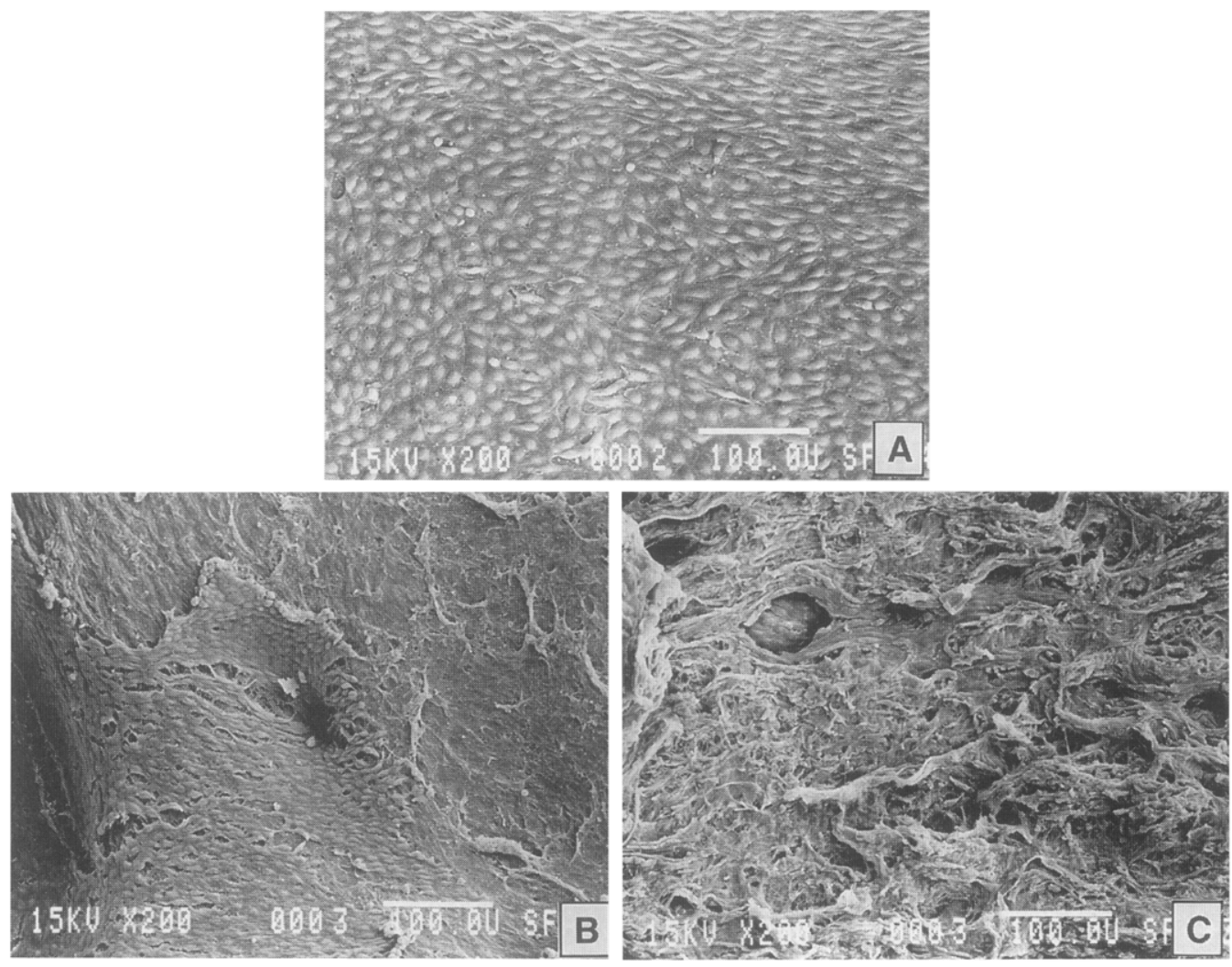

Fig. 4. SEM examination. A, Explanted autograft showing confluent endothelial-like cell lining in midportion of graft (original magnification $\times 200$ ). B, Proximal region of a thrombosed untreated histoincompatible allograft explanted at 4 weeks with partial colonization by endothelial-like cells and exposition of subendothelium to blood flow (original magnification $\times 200$ ). C, Midportion of an allograft denuded of ECs, with deposition of thrombotic material onto the luminal surface (original magnification $\times 200)$.

patible venous allografts in our study are the targets of both cell-mediated and humoral immune reactions, MMF should represent a suitable immunosuppressive agent in preventing immune-mediated allograft failure. MMF was shown to effectively reverse acute renal allograft rejection ${ }^{36}$ and to be as effective as azathioprine in combined immunosuppressive therapy in heart transplantation. ${ }^{37}$ It was also shown to significantly prolong dog renal allograft survival at a low dosage of 20 $\mathrm{mg} / \mathrm{kg}$ per day. ${ }^{38}$ Although this dosage is suboptimal, it was used in the present study, because higher dosages induce toxic side effects (gastrointestinal toxicity).

In our study, CsA treatment at a low dosage of 10 $\mathrm{mg} / \mathrm{kg}$ per day for a period of 4 weeks did not prevent allograft occlusion beyond 11 weeks. Moreover, $50 \%$ of autografts thrombosed within this group of dogs probably because of the formation of an angle within the graft in the immediate posttransplant period. This phenomenon could have accounted for autograft thrombosis because grafts, which were originally looped, failed before the first scheduled biopsy procedure. Although it has been reported that CSA can improve the patency of venous allografts, ${ }^{16,39,40}$ other investigators noted that short-term cyclosporine therapy did not eliminate later occlusion. ${ }^{13,29,41}$ Interestingly, posttransplant cytotoxic antibodies, in this group of dogs, reacted mostly against donor EC antigens. Because reactivity against donor splenocytes was observed in only one case without cytotoxic activity, we can suppose that MHC antigens were not involved in the sensitization of the CsA-treated hosts. Even though mild to moderate mononuclear cell infiltration was seen in CsA-treated allografts, no alloreactive lymphocytes could be cultured from the grafts. Donorspecific antibodies and other mechanisms such as 

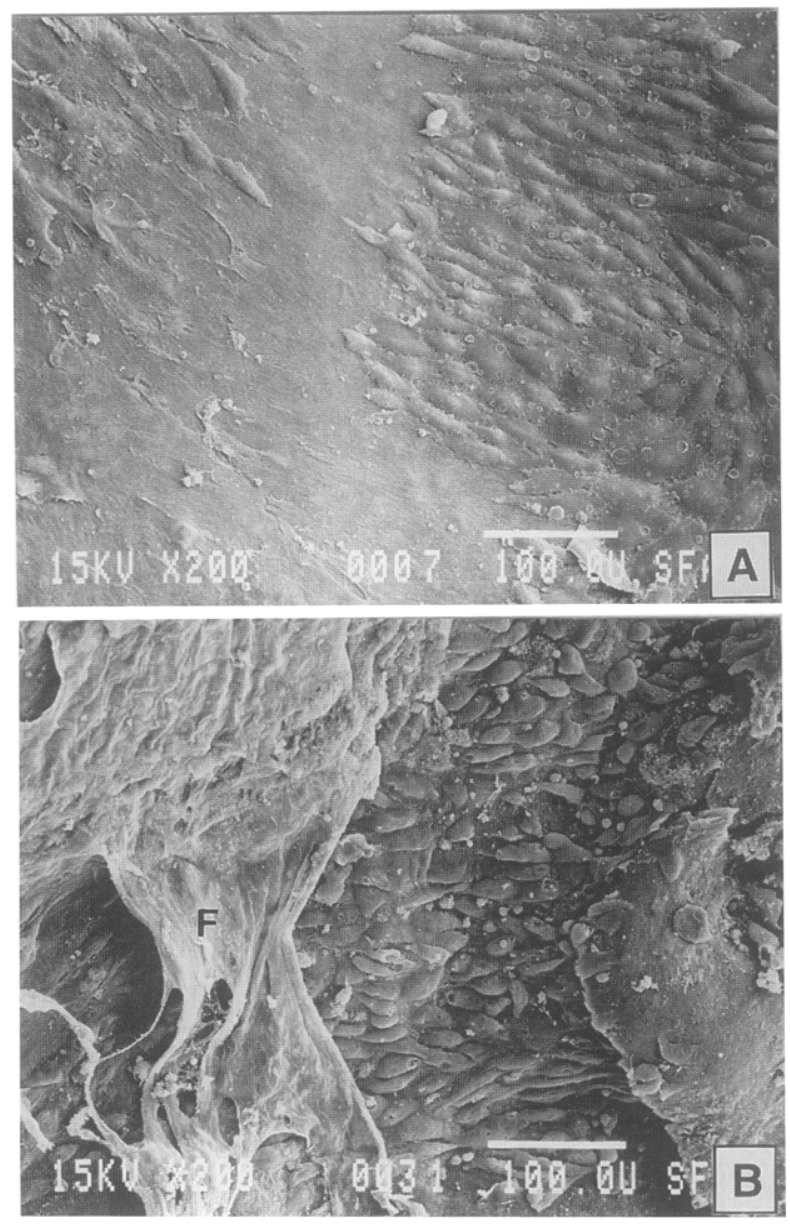

Fig. 5. Scanning electron micrographs (original magnification $\times 200$ ) of allograft retrieved at 20 weeks from a dog that was treated with CsA and MMF. Anastomotic regions showed almost complete covering of luminal surface with endothelial-like cells without fibrin or thrombotic matrix deposition (A), whereas midportion revealed presence of endothelial-like cells along with thin fibrin $(F)$ deposition (B).

natural killer cell allorecognition ${ }^{42}$ could have accounted for graft failure in this case.

MMF monotherapy did not produce better results. Indeed, none of the allografts was patent at 8 weeks (Table I). Because graft-infiltrating lymphocytes did not grow (mostly obtained at the dog's death), we can postulate that this treatment was partially effective, in as much as antibody development was measured against donor splenocytes. Of particular interest is that ECs could not be cultured in three dogs treated with MMF and in two dogs treated with CsA plus MMF. In fact, it has recently been reported that MMF can inhibit EC growth in vitro. ${ }^{43}$

Despite the poor efficacy of CsA and MMF monotherapies, the combined immunosuppressive treatment of CsA and MMF yielded a $100 \%$ allograft patency rate at 20 weeks. Antibodies were measured in the serum of one out of four dogs, reacting with donor splenocytes and ECs but without cytotoxic reactivity. Furthermore, no graft-infiltrating lymphocytes could be cultured from the allografts, which suggests a potent effect on the immune response. Thin mural thrombotic material was observed mainly in the midportion of the explanted allografts (Fig. 3), demonstrating damage toward graft ECs or an effect of MMF, because ECs could not be cultured in $50 \%$ of these dogs either at the time of operation or when they were killed. Intimal hyperplasia was not concentric and was observed mostly in the midportions of grafts (Fig. 3, $C$ ); however, it did not lead to graft occlusion as in dogs that received an MHC-compatible allograft. Thus we can state that treatment with two powerful immunosuppressants such as CsA and MMF, acting on two different stages of immune cell activation, led to alloreactive recognition inactivation and that a certain form of immune tolerance to the graft was established. The addition of MMF to CsA certainly helped in gaining immune tolerance to the allograft because CsA alone precludes reaching allograft tolerance in dogs. ${ }^{44}$ In addition, when used at the same dosages as in our experiments, CsA and MMF prolong the survival of hepatic allografts in dogs, ${ }^{45}$ demonstrating the efficacy of the combined immunotherapy. A synergistic interaction between the two immunosuppressants could be responsible for the $100 \%$ patency rate observed. However, it would have been helpful to measure blood concentrations of CsA and MMF to assess this possibility. Nevertheless, immunosuppression with CsA or MMF alone was done with suboptimal dosages. Further experiments should be done to establish the optimal dosages to use in dogs and then to determine the efficacy as compared with CsA-MMF therapy. Still, in our venous allograft model, MMF seems to be an appropriate immunosuppressant, and it was recently shown to prevent intimal thickening in a rat aortic allograft model ${ }^{46}$ by inhibiting smooth muscle cell growth. ${ }^{45}$ This characteristic is important in arterial reconstruction with the use of venous tissues because approximately $50 \%$ of peripheral bypass grafts fail within 5 years because of intimal hyperplasia. ${ }^{47}$ This effect of MMF on intimal hyperplasia could 
explain the better results obtained with allografts from dogs treated with CsA and MMF.

Although a limited number of dogs was used, this study indicates that the use of fresh vein allografts with short-term treatment with CsA and MMF in combination could lead to long-term acceptance of this allogeneic tissue. However, further studies involving a higher number of allograft recipients and longer follow-up periods will be necessary to assess the exact role of this immunosuppressive treatment on the outcome of venous allografts used as smalldiameter arterial substitutes.

We thank Louisette Martin, Jacques Bastien, Marielle Corriveau, and Suzanne Bourassa for their skillful technical assistance. Cyclosporine was kindly provided by Sandoz Canada Inc., Dorval, Quebec, Canada, and MMF by Syntex Inc., Palo Alto, California. We extend our gratitude to Ethicon Inc., Peterborough, Ontario, Canada, for providing sutures and to Glaxo Inc., Mississauga, Ontario, Canada, for the generous gift of heparin.

\section{REFERENCES}

1. Okies JE, Page US, Bigelow JC, Krause AH, Salomon NW. The left internal mammary artery: the graft of choice. Circulation 1984;70 (Suppl):I213-21.

2. Lytle BW, Loop FD, Cosgrove DM, Ratliff NB, Easly $\mathrm{K}$, Taylor PC. Long-term (5-12 years) serial studies of internal mammary artery and saphenous vein coronary artery grafts. J THORAC CARdiovasc Surg 1985; $89: 248-58$.

3. Sonnenfeld T, Cronestrand R. The advantages of the great saphenous vein as a femoro-popliteal graft: a report on its clinical use. Scand J Thorac Cardiovasc Surg 1980;14:285-90.

4. Taylor LM Jr, Phinney ES, Porter LM. Present status of reverse vein bypass for lower extremity revascularization. J Vasc Surg 1986;3:288-97.

5. Wagner E, Guidoin R, Marois M, et al. Histopathological findings in synthetic and biological explanted grafts used in peripheral arterial reconstruction. ASAIO J 1994;40:M279-83.

6. Koebelé F, Guidoin R, Fabre JL, et al. Les homogreffes veineuses comme pontages fémoro-poplités ou comme abords vasculaires pour l'hémodialyse itérative. J Chir (Paris) 1984;121:283-92.

7. Jackson DR, Abel DW. The homologous saphenous vein in arterial reconstruction. Vasc Surg 1972;6:85-92.

8. Tice DA, Santoni E. Use of saphenous vein homografts for arterial reconstruction: a preliminary report. Surgery 1970;67:493-8.

9. Stephen M, Sheil AGR, Wong J. Allograft vein arterial bypass. Arch Surg 1978;113:591-3.

10. Axthelm SC, Porter JM, Strickland S, Baur GM. Antigenicity of venous allografts. Ann Surg 1979;189:290-3.

11. Harjola P-T, Scheinin TM, Tilikainen A. Factors affect- ing early patency of human venous allografts in arterial reconstruction. Ann Clin Res 1969;1:169-76.

12. Mehri Y, Roy R, Douville Y, et al. Fresh venous autografts and allografts as carotid substitutes in matched dogs from the same litter. $J$ Cardiovasc Surg 1990;1:147-55.

13. Stevens SL, Tyler JD, Freeman MB, et al. Factors affecting patency of venous allografts in miniature swine. J Vasc Surg 1990;12:361-6.

14. Williams GM, ter Haar A, Krajewski C, Parks LC, Roth J. Rejection and repair of endothelium in major vessel transplants. Surgery 1975;78:694-706.

15. Ricotta JJ, Collins GJ, Rich NM, Reynolds DG. Failure of immunosuppression to prolong venous allograft survival. Arch Surg 1980;115:99-101.

16. Bandlien KO, Toledo-Pereyra LH, MacKenzie GH, Choudhury SP, Cortez JA. Immunosuppression with cyclosporine: a new approach to improve patency of venous allografts. Arch Surg 1983;118:829-33.

17. Ladin DA, Lindenauer SM, Burkel WE, et al. Viability, immunologic reaction, and patency of cryopreserved venous allografts. Surg Forum 1982;33:460-3.

18. Brockbank KGM, McNally RT, Walsh KA. Cryopreserved vein transplantation. J Card Surg 1992;7:170-6.

19. Harris RW, Schneider PA, Andros G, Oblath RW, Salles-Cuhna S, Dulawa L. Allograft vein bypass: is it an acceptable alternative for infrapopliteal revascularization? J Vasc Surg 1993;18:553-60.

20. Wagner E, Roy R, Marois Y, Douville Y, Guidoin R. Posttransplant antibodies and fresh venous allograft failure in dogs. Transplantation 1994;58:537-42.

21. Deeg HJ, Raff RF, Grosse-Wilde H, et al. Joint report of the third international workshop on canine immunogenetics: I-analysis of homozygous typing cells. Transplantation 1986;41:111-7.

22. Jaffe EA, Nachman RL, Becker CG, Minick CR. Culture of human endothelial cells derived from umbilical veins. J Clin Invest 1973;52:2745-56.

23. Dal Col RH, Zeevi A, Rabinowich $H$, Herlan DB, Yousem SA, Griffith BP. Donor-specific cytotoxicity testing: an advance in detecting pulmonary allograft rejection. Ann Thorac Surg 1990;49:754-8.

24. Perloff LJ, Reckard CR, Rowlands DT, Barker CF, The venous homograft: an immunological question. Surgery 1972;72:961-70.

25. Ochsner JL, Lawson JD, Eskind SJ, Mills NL, DeCamp PT. Homologous vein as an arterial substitute: long-term results. J Vasc Surg 1984;1:306-13.

26. Gelbfish J, Jacobowitz IJ, Rose DM. Cryopreserved homologous saphenous vein: early and late patency in coronary artery bypass surgical procedures. Ann Thorac Surg 1986;42:70-3.

27. Marcuson RW, Arthur JF, Martson A. Fresh-vein allografts. Br J Surg 1969;56:513-7.

28. Vermassen F, Degrieck N, De Kock L, Goubeau J, Van Landuyt K, Derom F. Venous allografts for vascular reconstructions. J Cardiovasc Surg 1992;33:641-9. 
29. Deaton DW, Stephen JK, Karp RB, et al. Evaluation of cryopreserved allograft venous conduits in dogs. $\mathbf{J}$ Thorac Cardiovasc Surg 1992;103:153-62.

30. Miltenburg AMM, Meijer-Paape ME, Daha MR, et al. Donor-specific lysis of human kidney proximal tubular epithelial cells by renal allograft-infiltrating lymphocytes. Transplantation 1989;48:296-302.

31. Vaessen LMB, Baan CC, Ouwehand AJ, et al. Acute rejection in heart transplant patients is associated with the presence of committed donor-specific cytotoxic lymphocytes in the graft but not in the blood. Clin Exp Immunol 1992;88:213-9.

32. Calhoun AD, Baur GM, Porter JM, Houghton DH, Templeton JW. Fresh and cryopreserved venous allografts in genetically characterized dogs. J Surg Res 1977;22:687-96.

33. Kahan BD. Cyclosporin. N Engl J Med 1989;321: 1725-38.

34. Andrus L, Lafferty KJ. Inhibition of T-cell activity by cyclosporine A. Scand J Immunol 1981;15:449-58.

35. Allison AC, Eugui EM, Sollinger HW. Mycophenolate mofetil (RS-61443): mechanisms of action and effects in transplantation. Transplant Rev 1993;7:129-39.

36. Deierhoi MH, Kauffman RS, Hudson SL, et al. Experience with mycophenolate mofetil in renal transplantation at a single center. Ann Surg 1993;217:476-84.

37. Ensley RD, Bristow MR, Olsen SL, et al. The use of mycophenolate mofetil (RS-61443) in human heart transplant recipients. Transplantation 1993;56:7582.

38. Platz KP, Eckhoff DE, Hullett DA, Sollinger HW. Prolongation of dog renal allograft survival by RS61443, a new, potent immunosuppressive agent. Transplant Proc 1991;23:497-8.
39. Vermassen F, Degrieck N, De Kock L, et al. Immunosuppressive treatment of venous allografts. Eur $\mathrm{J}$ Vasc Surg 1991;5:669-75.

40. Vermassen F, Derom A, Janzing H, Derom F. Immunosuppressive treatment of venous allografts in dogs. J Thorac Cardiovasc Surg 1994;107:614-6.

41. Augelli NV, Lupinetti FM, El Khatib H, Sanofsky SJ, Rossi NP. Allograft vein patency in a canine model: additive effects of cryopreservation and cyclosporine. Transplantation 1991;52:466-70.

42. Trinchieri G. Recognition of major histocompatibility complex class I antigens by natural killer cells. J Exp Med 1994;180:417-21.

43. Young CJ, Sollinger HW. Mycophenolate mofetil (RS-61443). In: Przepiorka D, Sollinger H, eds. Recent developments in transplantation medicine: new immunosuppressive drugs. Glenview, Illinois: Physicians \& Scientists Publishing, 1994:93-110.

44. Deeg HJ, Storb R, Gerhard-Miller L, Shulman HM, Weiden PL, Thomas ED. Cyclosporin A, a powerful immunosuppressant in vivo and in vitro in the dog, fails to induce tolerance. Transplantation 1980;29: 230-5.

45. Bechstein WO, Schilling M, Steele DM, Hullett DA, Sollinger HW. RS-61443/cyclosporin combination therapy prolongs canine liver allograft survival. Transplant Proc 1993;25:702.

46. Steele DM, Bechstein WO, Kowalski J, et al. Effects of immunosuppressive therapy on the rat aortic allograft model. In: Abstracts of the Fourteenth International Congress of the Transplantation Society, Paris, France, 1992: Abstract 293.

47. Towne JB. Role of fibrointimal hyperplasia in vein graft failure. J Vasc Surg 1989;10:583-5. 